\title{
Evaluation of factors influencing maternal and fetal outcome in eclampsia in a tertiary care hospital
}

\author{
Paresh Shyam*, Anjuman Alam, Kalyan Nath
}

Department of Obstetrics \& Gynaecology, Assam Medical College, Dibrugarh, Assam, India

Received: 21 December 2015

Accepted: 06 January 2016

\author{
*Correspondence: \\ Dr. Paresh Shyam, \\ E-mail: pareshshyam@gmail.com
}

Copyright: () the author(s), publisher and licensee Medip Academy. This is an open-access article distributed under the terms of the Creative Commons Attribution Non-Commercial License, which permits unrestricted non-commercial use, distribution, and reproduction in any medium, provided the original work is properly cited.

\begin{abstract}
Background: Eclampsia is a major cause of maternal morbidity and mortality in developing countries. Evaluation of factors contributing to occurrence of eclampsia and death of eclamptic mother is of paramount importance.

Methods: A retrospective study of two years period was done in Assam Medical College, Dibrugarh. Pregnant woman diagnosed as eclampsia during this period were included. The events and outcome of mother and fetus were recorded and analysed.

Results: During this two years period the total number of deliveries were 19150, total maternal death 180, eclampsia case 406 and maternal death due to eclampsia was 29 . The incidence of eclampsia was $2.12 \%$, case fatality rate $7.14 \%$, stillbirth $16.29 \%$ and caesarean delivery in eclamptic mother was $30 \%$. Pulmonary edema (34.48\%) and anaemic heart failure $(27.58 \%$ ) were responsible for majority of the maternal death.

Conclusions: Eclampsia is still a major cause of maternal death. Occurrence of eclampsia can be reduced by optimizing antenatal care of pregnant woman of low socioeconomic class. Improvement in capacity of intensive care unit and blood bank are essential prerequisite to reduce maternal death due to eclamptic mother.
\end{abstract}

Keywords: Eclampsia, Maternal death, India

\section{INTRODUCTION}

Eclampsia is the occurrence of convulsion in a pregnant woman with preeclampsia. Eclampsia is a preventable complication of preeclampsia. Incidence of eclampsia varies between developing countries and developed countries. Though rare in developed countries incidence of eclampsia is not uncommon in India. Maternal death associated with hypertensive disorder of pregnancy contributes $10 \%$ of maternal death (Khan KS 2006 WHO). ${ }^{1}$ Eclampsia is still a major cause of maternal death in India (24.09\%, FOGSI study). ${ }^{2}$ A number of complications associated with eclampsia is responsible for high rate of maternal death in eclampsia. ${ }^{3-5}$ It is essential to know the sociodemographic background of women suffering from eclampsia, complication associated with eclampsia and factors influencing maternal and fetal outcome in order to formulate effective strategy for reducing the number of cases of eclampsia and for improving outcome of mother and foetuses in eclampsia.

The objectives of this study were as following.

1. To measure the incidence of eclampsia.

2. To evaluate the maternal outcome.

3. To document and analyse the sociodemographic background of eclamptic women. 


\section{METHODS}

\section{Source of data}

This retrospective study was carried out in woman with eclampsia in the department of Obstetrics and Gynaecology, Assam Medical College, Dibrugarh, India.

\section{Settings}

Assam Medical College, Dibrugarh, India

\section{Study period}

The period of this study was from January 2013 to December 2014.

\section{Study design}

It was a retrospective clinical study

\section{Patient selection}

\section{Inclusion criteria}

All cases of pregnant woman diagnosed as eclampsia at admission or who developed eclampsia during stay at hospital were included.

\section{Exclusion criteria}

1. The pregnant woman with known seizure disorders were excluded from study population.

2. Patients with onset of convulsion after 10 days of delivery were excluded.

Data were collected from records of labour room and Caesarean section operation theatre.

\section{Operational definition}

\section{Booked Case}

Woman were labelled as booked case if she had minimum 4 antenatal check up by any health worker as per WHO guidelines.

\section{Pre-referral management}

Pre-referral management was considered adequate if patient received anticonvulsant magnesium sulphate before referral.

Magnesium sulphate was used to control convulsion as per Pritchard regimen in all cases.

\section{Outcome measures}

Maternal outcome

Maternal death and major complications.

\section{Fetal outcome}

Livebirth, Stillbirth.

\section{Statistical analysis}

Data were presented in terms of percentage and chi square test was applied for testing the significance.

\section{RESULTS}

During the study period the total number of deliveries was 19150 and total number of eclampsia 406. So the incidence of eclampsia was $2.12 \%$.

The age group of 15-20 years (41.6\%) was the largest group. Significantly more eclamptic woman were in this age group ( $\mathrm{P}<0.01)$. The number of eclampsia in booked cases $177(43.59 \%)$ was significantly less than unbooked cases $229(56.40 \%)(\mathrm{P}<0.01)$.

Table 1: Age group distribution.

\begin{tabular}{|ll|ll|}
\hline Age group & 2013 & 2014 & Total $(\%)$ \\
\hline 15-20 years & 98 & 71 & $169(41.62 \%)$ \\
\hline 21-25 years & 95 & 57 & $152(37.43 \%)$ \\
\hline 26-30 years & 25 & 50 & $75(18.47 \%)$ \\
\hline 31-35 years & 5 & 2 & $7(1.72 \%)$ \\
\hline 35-40 years & 1 & 2 & $3(0.73)$ \\
\hline Total & 224 & 182 & 406 \\
\hline
\end{tabular}

The maximum number of patient was primigravidae 338 $(83.25 \%)$.

The number of cases of antepartum eclampsia was 355 $(87.43 \%)$, intrapartum eclampsia 49 (12\%) and postpartum eclampsia $2(0.49 \%)$.

Most of the woman had vaginal deliveries 279 (69.92\%). Caesarean delivery was conducted in 120 (30.07\%) women and 7 women remain undelivered.

The total maternal death in the study period was 180 and the maternal death due to eclampsia was 29 . Thus eclampsia contributed $16.11 \%$ maternal death. The case fatality rate (CFR) was $7.14 \%$.

The cause of maternal death was pulmonary oedema /aspiration in $13(44.8 \%)$ cases, anaemic heart failure 8 (27.5\%), Cerebrovascular accident (CVA) 4 (13.7\%), septicaemia $2(6.8 \%)$ and Acute renal failure (ARF) 2 $(6.8 \%)$ cases. 


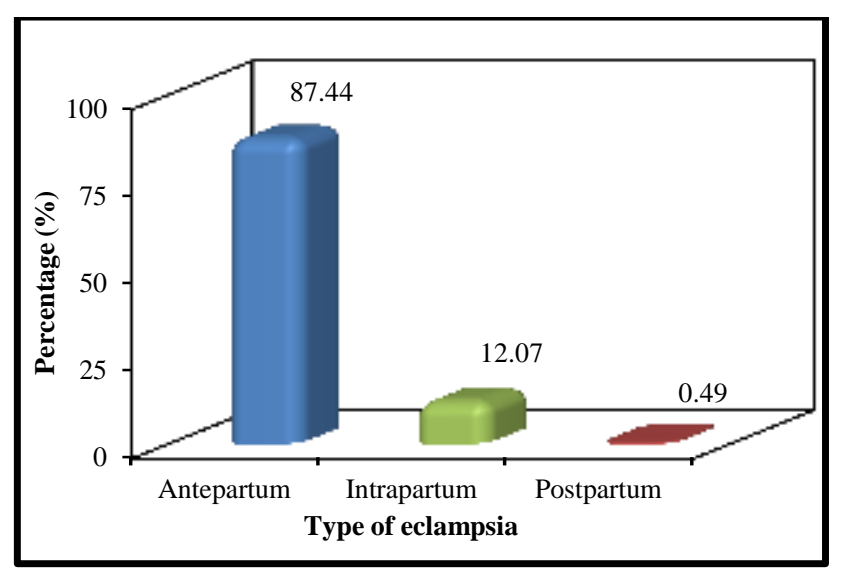

Figure 1: Type of eclampsia.

Table 2: Cause of death.

\begin{tabular}{|llll|}
\hline Cause of death & 2013 & 2014 & Total (\%) \\
\hline Pulmonary edema & 6 & 4 & $10(34.48 \%)$ \\
\hline Anaemic heart failure & 2 & 6 & $8(27.58 \%)$ \\
\hline $\begin{array}{l}\text { Cerebrovascular } \\
\text { accident }\end{array}$ & 4 & 0 & $4(13.79 \%)$ \\
\hline Aspiration & 1 & 2 & $3(10.34 \%)$ \\
\hline Acute renal failure & 1 & 1 & $2(6.89 \%)$ \\
\hline Septicemia & 1 & 1 & $2(6.89 \%)$ \\
\hline Total & 15 & 14 & $29(100 \%)$ \\
\hline
\end{tabular}

The number of livebirth was $334(83.70 \%)$ and stillbirth $65(16.29 \%)$.

\section{DISCUSSION}

\section{Incidence}

The incidence was found to be $2.12 \%(212 / 10000)$ which is similar to study reported by Majhi AK $(2.79 \%)$ and Das R, 2.627\% but much higher than developed countries. ${ }^{6,7}$ The incidence in UK is $4.9 / 10000$, Canada 5.9 per 10000 and Netherlands $6.2 / 10000 .^{3,4,8}$

\section{Gravidity}

Maximum number of woman were primigravidae $(87.44 \%)$ in our study which is similar to study by Sarma HK $(85 \%){ }^{9}$

\section{Age}

The age group of 15-20 years was the largest group (41.62\%) of eclamptic woman and 21-25 years age group was second $(37.43 \%)$ whereas Agida reported that 20-24 years age group was the largest $34.8 \%$ and $25-29$ years was second $26.1 \% .^{9}$ Liu S reported maximum number of eclampsia in the 20-24 years age group (18.1/10000) and second group $\geq 40$ years $11.4 / 10000 .{ }^{4}$ The practice of teen age marriage may be the reason for this young age group contributing the largest number of patients. Teen age pregnancies have higher risk of complication. The age of $79 \%$ of woman with eclampsia was 25 years or less.

\section{Antenatal care}

In the present study the number of booked case was (43.6\%). Edgar M, reported $96 \%$ cases as booked ${ }^{11}$. Douglas KA reported $70 \%$ cases of eclampsia had antenatal care ${ }^{3}$. This indicates lack of desired impact of antenatal visit/care on occurrence of eclampsia. Thus the inadequacy of content of antenatal care or inadequate number of antenatal visit in the crucial period of third trimester of pregnancy is reflected. Creating awareness and educating about danger of high blood pressure and danger signs of preeclampsia will help in reducing occurrence of eclampsia.

\section{Type of eclampsia}

The number of cases of antepartum eclampsia was maximum $(87.44 \%)$. Douglas KA reported antepartum eclampsia $38 \%$, intrapartum $18 \%$ and postpartum $44 \%$. Study of Vijayasree $\mathrm{M}$ et al found antepartum eclampsia $(71 \%)$ cases as the largest group. ${ }^{12}$

\section{Adequacy of referral}

Most of the patients presented to our hospital without receiving anticonvulsant drugs $\left(\mathrm{MgSO}_{4}\right)$. Similar observation was made by Pannu D. ${ }^{13}$ As the number of convulsion increases maternal as well as fetal mortality and morbidity increases. Patients must receive anticonvulsant drugs before referral to prevent recurrence of convulsion during highly vulnerable period of transportation.

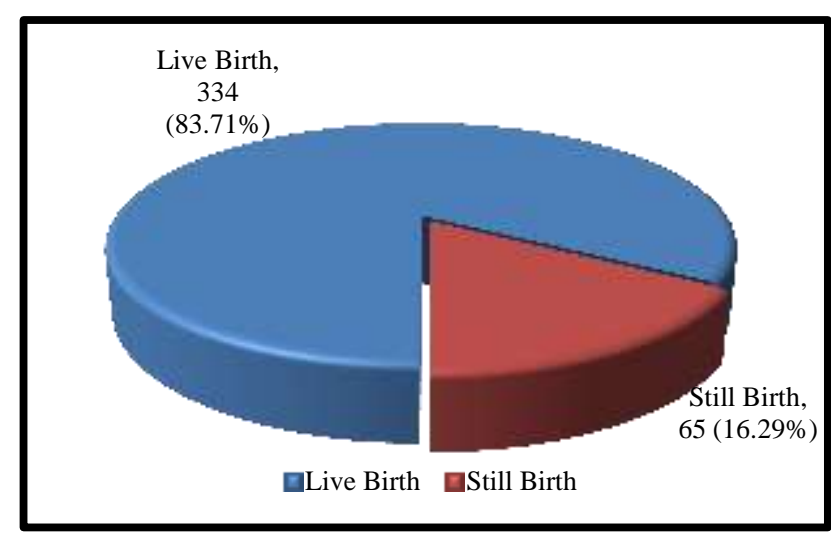

Figure 2: Livebirth and stillbirth.

\section{Stillbirth}

The stillbirth found in the present study was $16.29 \%$ (65) which is similar to study reported by Agida (17.4\%), Pannu D (18.85\%) and Edgar M (12.2\%). ${ }^{10,11,13}$ Study of Liu S reported fetal death $10.8 / 1000 .^{4}$ The maximum 
number of stillbirth was due to intrauterine fetal death (IUFD) taking place before admission to hospital.

\section{Caesarean deliveries}

The number of woman delivered by caesarean section was $110(30.07 \%)$ which is similar to Nwobodo $(26.5 \%)$ but much lower than reported by Agida et al (84.8\%). ${ }^{10,14}$ The lower rate of caesarean section operation is due to higher surgical or anaesthetic risk of eclamptic woman. Eclamptic woman with critical condition like pulmonary edema with or without severe anaemia or unconscious make them unfit for caesarean operation.

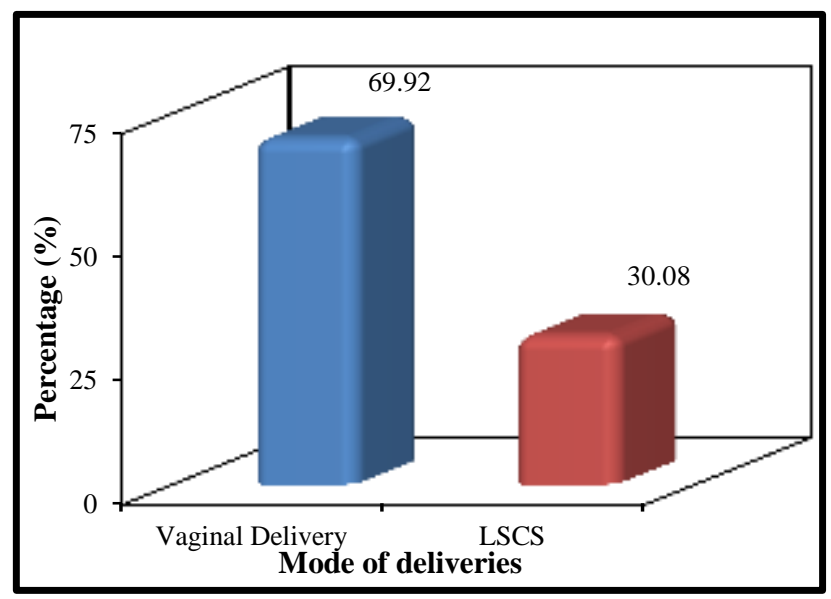

Figure 3: Mode of deliveries.

\section{Maternal death}

Globally hypertensive disorder of pregnancy contribute $10 \%$ of maternal death whereas in our study it was found that eclampsia alone is contributing $16.11 \%$ of maternal death. ${ }^{1}$ Other studies have shown much higher percentage $(48.76 \%, 43.35 \%, 45.36 \%) .{ }^{6,7,15}$

Pulmonary edema (34.48\%)/aspiration (10.34\%) and anaemic heart failure $(27.58 \%)$ were cause of death in $73 \%$ maternal death. These $73 \%$ cases can only be properly managed with ventilatory support in ICU (Intensive care unit) and adequate supply of blood or blood component.

The number of woman dying within 24 hours of admission was 17 (51.62\%). Olopade reported $85.7 \%$ and Das $88.46 \%$ of the eclamptic deaths occurring within 24 hours of hospital admission. ${ }^{7,16}$ This indicates late arrival at tertiary care hospital or inadequate provision of supportive care at the referral hospital.

Pulmonary edema $(10 / 17,58.8 \%)$ and anaemic heart failure $(5 / 17,29.4 \%)$ was together responsible in $88.2 \%$ cases of maternal death within 24 hours of admission in hospital.
Severe anaemia was found to be a major cause of maternal death $(29.4 \%)$ in the study. Death of these women could have been averted by correction of anaemia during antenatal period by oral or injectable iron.

Case fatality rate (CFR) was $7.14 \%$ which is similar to reported by Adiga et al but higher than reported by Sarkar $\mathrm{M}$ et al $(4.96 \%)$.

The factors responsible for high maternal death or CFR was late arrival in tertiary care hospital, moribund condition of the patients at the time of admission, lack of provision of ICU facility in adequate number and nonavailability of blood or blood component in sufficient quantity.

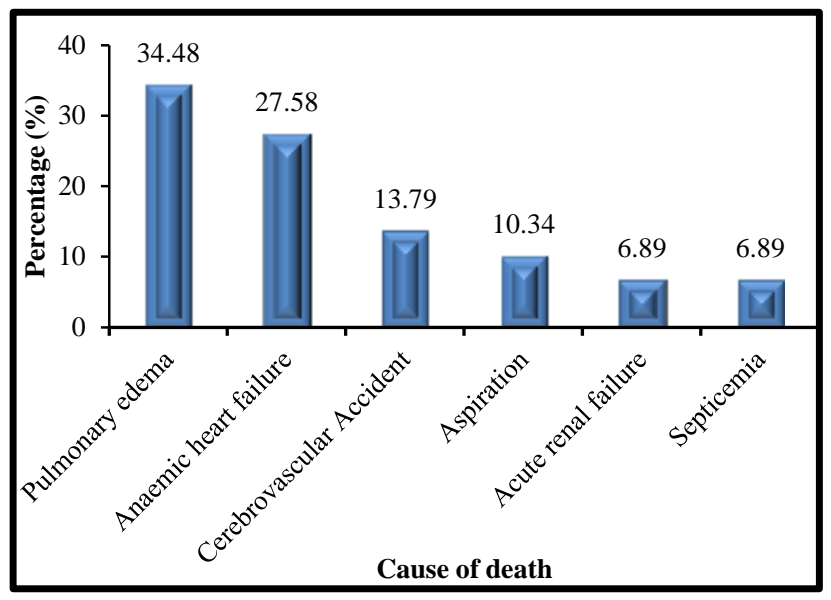

Figure 4: Cause of death.

\section{CONCLUSIONS}

Eclampsia is a major cause of maternal death in India. To reduce the maternal mortality due to eclampsia there must be primary as well as secondary prevention. The occurrence of eclampsia can be reduced by early diagnosis and treatment of preeclampsia through adequate antenatal care. As the most of the women are from low socioeconomic condition, strategy needs to be developed to optimise antenatal care of this group of women. The tertiary level care hospital where these cases are treated need to have ICU facility with provision of sufficient number of bed. Blood bank must have enough blood or blood component to meet the need of these eclamptic mothers. We hope to achieve better outcome with these measures.

\section{ACKNOWLEDGEMENTS}

Authors would like to thank Department of Obstetrics \& Gynaecology, Assam Medical College \& Hospital, Dibrugarh, Assam, India.

\section{Funding: No funding sources \\ Conflict of interest: None declared \\ Ethical approval: Not required}




\section{REFERENCES}

1. Khan KS, Wojdyla D, Say L, Gülmezoglu AM, Van Look PF. WHO analysis of causes of maternal death: a systematic review. Lancet. 2006;367(9516):106674.

2. Konar H, Chakraborty AB. Maternal Mortality: A FOGSI Study (Based on Institutional Data). The Journal of Obstetrics and Gynecology of India. 2013;63(2):88-95.

3. Douglas KA, Redman CWG. Eclampsia in the United Kingdom. Br Med J. 1994;309(6966):1395400 .

4. Shiliang L, Joseph KS, Liston RM, Bartholomew S, Walker M, Leo'n JA, et al. Incidence, Risk Factors, and Associated Complications of Eclampsia. Obstetrics \& gynecology. 2011;118(5):987-94.

5. Lee W, O'Connell CM, Baskett TF. Maternal and perinatal outcomes of eclampsia: Nova Scotia, 19812000. J Obstet Gynaecol Can. 2004;26(2):119-23.

6. Majhi AK, Chakraborty PS, Mukhopadhyay A. Eclampsia-Present scenario in a Referral Medical College Hospital. J Obstet Gynecol Ind. 2001;51:143-7.

7. Das R, Biswas S. Eclapmsia: the major cause of maternal mortality in eastern india. Ethiop $\mathrm{J}$ Health Sci. 2015;25(2):111-6.

8. Zwart J, Richters A, Ory F, Vries J, Bloemenkamp $\mathrm{K}$, Roosmalen J. Eclampsia in the Netherlands. Obstet Gynaecol. 2008;112:820-7.

9. Sarma HK, Talukdar B. Eclampsia: a clinical prospective study in a referral hospital. Journal of Obstetrics \& Gynaecology Barpeta. 2014;1(1):57-61.

10. Agida TE, Adeka BI, Jibril KA. Pregnancy outcome in eclamptics at the university ofabuja teaching hospital, gwagwalada, abuja: a 3 year review. Nigerian Journal of Clinical Practice. 2010;13(4):394-8.

11. Ndaboine EM, Kihunrwa A, Rumanyika R, IM HB, Massinde AN. Maternal and perinatal outcomes among eclamptic patients admitted to Bugando medical centre, Mwanza, Tanzania. Afr J Reprod Health. 2012;16(1):35-41.

12. Vijayasree M, Murali GV. A Clinical study of perinatal and maternal complications in Eclampsia in a tertiary care Referral Centre - A Near Miss Obstetric catasthrope. International Journal of Advanced Multidisciplinary Research. 2015;2(4):805.

13. Pannu D, Das B, Hazari P, Shilpa. Maternal and perinatal outcome in eclampsia and factors affecting the outcome: a study in North Indian population. Int J Reprod Contracept Obstet Gynecol. 2014;3(2):34751.

14. Nwobodo EI, Ahmed Y. Maternal mortality associated with eclampsia in Sokoto, Nigeria. OJM 2011;23(1-4);49-53.

15. Sarkar M, Basak S, Mondal SK, Das S, Roy D, Mandal J, et al. Maternal mortality associated with eclampsia in an Indian medical college: a four year retrospective study. J Med Sci. 2013;4(10):394-8.

16. Olopade FE, Lawoyin TO. Maternal Mortality in a Nigerian Maternity Hospital African Journal of Biomedical Research. 2008;11:267-73.

Cite this article as: Shyam $\mathrm{P}$, Alam A, Nath K. Evaluation of factors influencing maternal and fetal outcome in eclampsia in a tertiary care hospital. Int $\mathbf{J}$ Reprod Contracept Obstet Gynecol 2016;5:280-4. 